\title{
Lixisenatide in Patients with Type 2 Diabetes and Acute Coronary Syndrome
}

\author{
Marc A. Pfeffer, M.D., Ph.D., Brian Claggett, Ph.D., Rafael Diaz, M.D., \\ Kenneth Dickstein, M.D., Ph.D., Hertzel C. Gerstein, M.D., Lars V. Køber, M.D., \\ Francesca C. Lawson, M.D., Lin Ping, M.D., Xiaodan Wei, Ph.D., \\ Eldrin F. Lewis, M.D., M.P.H., Aldo P. Maggioni, M.D., \\ John J.V. McMurray, M.D., Ph.D., Jeffrey L. Probstfield, M.D., \\ Matthew C. Riddle, M.D., Scott D. Solomon, M.D., and Jean-Claude Tardif, M.D., \\ for the ELIXA Investigators*
}

A BSTRACT

BACKGROUND

Cardiovascular morbidity and mortality are higher among patients with type 2 diabetes, particularly those with concomitant cardiovascular diseases, than in most other populations. We assessed the effects of lixisenatide, a glucagon-like peptide 1-receptor agonist, on cardiovascular outcomes in patients with type 2 diabetes who had had a recent acute coronary event.

\section{METHODS}

We randomly assigned patients with type 2 diabetes who had had a myocardial infarction or who had been hospitalized for unstable angina within the previous 180 days to receive lixisenatide or placebo in addition to locally determined standards of care. The trial was designed with adequate statistical power to assess whether lixisenatide was noninferior as well as superior to placebo, as defined by an upper boundary of the $95 \%$ confidence interval for the hazard ratio of less than 1.3 and 1.0, respectively, for the primary composite end point of cardiovascular death, myocardial infarction, stroke, or hospitalization for unstable angina.

\section{RESULTS}

The 6068 patients who underwent randomization were followed for a median of 25 months. A primary end-point event occurred in 406 patients $(13.4 \%)$ in the lixisenatide group and in 399 (13.2\%) in the placebo group (hazard ratio, 1.02; $95 \%$ confidence interval [CI], 0.89 to 1.17 ), which showed the noninferiority of lixisenatide to placebo $(\mathrm{P}<0.001)$ but did not show superiority $(\mathrm{P}=0.81)$. There were no significant between-group differences in the rate of hospitalization for heart failure (hazard ratio in the lixisenatide group, 0.96 ; $95 \%$ CI, 0.75 to 1.23 ) or the rate of death (hazard ratio, $0.94 ; 95 \% \mathrm{CI}, 0.78$ to 1.13 ). Lixisenatide was not associated with a higher rate of serious adverse events or severe hypoglycemia, pancreatitis, pancreatic neoplasms, or allergic reactions than was placebo.

\section{CONCLUSIONS}

In patients with type 2 diabetes and a recent acute coronary syndrome, the addition of lixisenatide to usual care did not significantly alter the rate of major cardiovascular events or other serious adverse events. (Funded by Sanofi; ELIXA ClinicalTrials.gov number, NCT01147250.)
From the Cardiovascular Division, Brigham and Women's Hospital, and Harvard Medical School - both in Boston (M.A.P., B.C., E.F.L., S.D.S.); Estudios Clínicos Latinoamérica, Rosario, Argentina (R.D.); University of Bergen, Stavanger University Hospital, Stavanger, Norway (K.D.); McMaster University, Hamilton, ON, Canada (H.C.G.); Rigshospitalet Copenhagen University Hospital, Copenhagen (L.V.K.); Sanofi U.S., Bridgewater, NJ (F.C.L., L.P., X.W.); Research Center of the Italian Association of Hospital Cardiologists, Florence (A.P.M.); British Heart Foundation Cardiovascular Research Centre, University of Glasgow, Glasgow, United Kingdom (J.J.V.M.); University of Washington Medical Center, Seattle (J.L.P.); Oregon Health and Science University, Portland (M.C.R.); and Montreal Heart Institute, Université de Montréal, Montreal (J.C.T.). Address reprint requests to Dr. Pfeffer at the Cardiovascular Division, Brigham and Women's Hospital, 75 Francis St., Boston, MA 02115, or at mpfeffer@rics.bwh.harvard.edu.

*A list of the investigators and committee members in the Evaluation of Lixisenatide in Acute Coronary Syndrome (ELIXA) trial is provided in the Supplementary Appendix, available at NEJM.org.

N Engl J Med 2015;373:2247-57. DOI: 10.1056/NEJMoa1509225 Copyright (C) 2015 Massachusetts Medical Society. 
$\mathrm{R}$ ANDOMIZED TRIALS INVOLVING PAtients with new or established type 2 diabetes have shown that improved glucose control reduces the risk of microvascular complications, ${ }^{1-3}$ with modest cardiovascular benefits suggested by meta-analyses and extended follow-up of clinical trials..$^{4-7}$ However, various studies indicate that, despite being effective in lowering the glucose and glycated hemoglobin levels, some hypoglycemic medications may increase, rather than reduce, the risk of cardiovascular events..$^{8-10}$ These unexpected findings prompted the reexamination of the regulatory approval processes for new antidiabetic therapies, which had been based primarily on the surrogate measure of glucose lowering with limited clinical-outcomes data. Since 2008, regulatory agencies have required robust cardiovascular-outcome data from randomized, controlled trials in order to grant and sustain approvals of drugs or biologic agents for the treatment or prevention of diabetes mellitus. ${ }^{11-13}$

Glucagon-like peptide 1 (GLP-1)-receptor agonists are a class of parenteral glucose-lowering drugs that activate the receptor for the endogenous incretin GLP-1. These drugs lower glucose levels by inhibiting the secretion of glucagon, promoting the release of insulin in response to hyperglycemia, slowing gastric emptying, and augmenting satiety. ${ }^{14}$ On the basis of some evidence of cardioprotection in preliminary studies in animal models ${ }^{15,16}$ and in pilot studies of myocardial ischemia ${ }^{17,18}$ and heart failure in humans, ${ }^{19}$ it was postulated ${ }^{20,21}$ that in addition to improving glycemic control and promoting weight loss, GLP-1-receptor agonists may improve cardiovascular outcomes.

Lixisenatide, a once-daily GLP-1-receptor agonist, is effective in reducing the glycated hemoglobin level in patients with type 2 diabetes by lowering both the fasting and the postprandial blood glucose levels..$^{22-25}$ However, the studies showing such glycemic control and other favorable metabolic effects of lixisenatide were not designed to accrue sufficient clinical events to adequately show its cardiovascular safety. Although lixisenatide and several other GLP-1-receptor agonists are approved in many countries for use as glucose-lowering agents in patients with type 2 diabetes, large cardiovascular-outcome trials with any agent in this class have been lacking.
METHODS

\section{STUDY DESIGN}

The Evaluation of Lixisenatide in Acute Coronary Syndrome (ELIXA) trial was a multicenter, randomized, double-blind, placebo-controlled trial involving patients with type 2 diabetes who had had a recent acute coronary syndrome. The trial was designed to assess the effects of lixisenatide on cardiovascular morbidity and mortality. Details of the trial design and the demographic and clinical characteristics of the patients at baseline have been reported previously. ${ }^{26}$ The study protocol, available with the full text of this article at NEJM.org, was designed by the executive committee, which also oversaw the conduct of the trial (see the Supplementary Appendix, available at NEJM.org).

The chair of the executive committee wrote the first draft of the manuscript, and all the coauthors contributed to the subsequent revisions. Data were analyzed and confirmed at two statistical centers (one at the sponsor's location and one at Brigham and Women's Hospital). Each author could query the database by requesting specific analyses or clarifications of definitions. All the authors edited and approved the manuscript and assume full responsibility for the accuracy and completeness of the data and for the fidelity of this report to the study protocol, which was approved by the appropriate national and institutional regulatory and ethics boards. All the patients provided written informed consent.

\section{STUDY PATIENTS}

Eligible patients had type 2 diabetes and had had an acute coronary event within 180 days before screening. Major exclusion criteria were an age of less than 30 years, percutaneous coronary intervention within the previous 15 days, coronary-artery bypass graft surgery for the qualifying event, planned coronary revascularization procedure within 90 days after screening, an estimated glomerular filtration rate (eGFR) of less than $30 \mathrm{ml}$ per minute per $1.73 \mathrm{~m}^{2}$ of bodysurface area, a glycated hemoglobin level of less than $5.5 \%$ or more than $11.0 \%$, or an inability to provide written informed consent. ${ }^{26}$ Before randomization, there was a 1-week run-in period during which eligible consenting patients were trained in the self-administration of daily subcu- 
taneous injections of unblinded placebo, with the volume matched to that of the injections they would receive after randomization.

\section{STUDY INTERVENTIONS}

Patients were randomly assigned, in a doubleblind manner, to once-daily subcutaneous injections of lixisenatide or volume-matched placebo. Randomization was performed with the use of a centralized assignment system. A starting dose of $10 \mu \mathrm{g}$ of lixisenatide per day or volumematched placebo was administered during the first 2 weeks and then increased, at the investigator's discretion, to a maximum dose of $20 \mu \mathrm{g}$ of lixisenatide per day or volume-matched placebo. Glycemic control was managed by the investigators in accordance with local clinical practice guidelines by the adjustment of concomitant glucose-lowering agents or the addition of new antidiabetic medications with the exception of other incretin therapies. This approach was expected to yield similar glycemic control in the two study groups.

\section{STUDY END POINTS}

The primary end point in the time-to-event analysis was a composite of the first occurrence of any of the following: death from cardiovascular causes, nonfatal myocardial infarction, nonfatal stroke, or hospitalization for unstable angina. Secondary end points included a composite of the primary end point or hospitalization for heart failure and a composite of the primary end point, hospitalization for heart failure, or coronary revascularization procedures. All-cause mortality and the rates of the components of each of the composite end points were examined.

Changes in the glycated hemoglobin level, urinary albumin-to-creatinine ratio, body weight, heart rate, and blood pressure were evaluated. Safety end points, including the incidence of hypoglycemia and severe hypoglycemia (requiring the assistance of another person), pancreatitis, cancer, and systemic allergic reactions, were assessed in patients who underwent randomization and received at least one dose of lixisenatide or placebo. Separate independent committees whose members were unaware of the studygroup assignments adjudicated potential cardiovascular, pancreatic, and allergic events (see the Supplementary Appendix).

\section{STUDY OVERSIGHT}

The data and safety monitoring committee, whose members had access to unblinded data, monitored the safety of the participants. When 144 adjudicated primary end-point events had occurred, the data and safety monitoring committee reviewed a prespecified, independently performed analysis of the unblinded data and informed the executive committee and the sponsor that the upper boundary of the resulting $96 \%$ confidence interval of the hazard ratio for the comparison of lixisenatide with placebo was less than 1.8 (see the Supplementary Appendix). ${ }^{9,11,27}$ At that time, a group from the sponsor, which was not in communication with the ELIXA team, prepared and subsequently filed a New Drug Application with the Food and Drug Administration, which was later withdrawn to avoid public disclosure of preliminary data.

\section{STATISTICAL ANALYSIS}

The primary analysis was conducted in the intention-to-treat population with the use of the Cox proportional-hazards model, with study group and geographic region as the covariates, to estimate the hazard ratio for the comparison of lixisenatide with placebo. The noninferiority of lixisenatide to placebo would be shown if the upper boundary of the $95 \%$ confidence interval of the hazard ratio was less than 1.3 and the superiority would be shown if the upper boundary was less than $1.0 .^{11}$ The $P$ values for the tests of noninferiority and superiority are derived from the Cox proportional-hazards model.

The trial was event-driven. We estimated that 6000 patients would need to be enrolled for us to observe 844 primary end-point events, which would provide the study with $96 \%$ power to show noninferiority, assuming a true hazard ratio of 1.0 , and with $90 \%$ power to show superiority, assuming a true hazard ratio of 0.80 . More complete details regarding sample-size assumptions have been published previously. ${ }^{26}$

Sensitivity analyses were conducted in which events that occurred more than 30 days after the discontinuation of lixisenatide or placebo were excluded; in addition, a post hoc Cox proportional-hazards analysis was conducted with a model that was adjusted for nominally significant baseline imbalances. Postbaseline measures were analyzed with the use of non- 


\begin{tabular}{|c|c|c|}
\hline Characteristic & Placebo ( $N=3034)$ & Lixisenatide $(\mathrm{N}=3034)$ \\
\hline Age $-y r$ & $60.6 \pm 9.6$ & $59.9 \pm 9.7$ \\
\hline Age $\geq 65$ yr - no. (\%) & $1040(34.3)$ & $1003(33.1)$ \\
\hline Female sex — no. (\%) & 938 (30.9) & $923(30.4)$ \\
\hline Duration of diabetes - yr & $9.4 \pm 8.3$ & $9.2 \pm 8.2$ \\
\hline Glycated hemoglobin — \% & $7.6 \pm 1.3$ & $7.7 \pm 1.3$ \\
\hline Retinopathy - no. (\%) & $331(10.9)$ & $320(10.5)$ \\
\hline Neuropathy - no. (\%) & $498(16.4)$ & $512(16.9)$ \\
\hline Body weight — kg & $85.1 \pm 19.6$ & $84.6 \pm 19.2$ \\
\hline Body-mass indext & $30.2 \pm 5.8$ & $30.1 \pm 5.6$ \\
\hline \multicolumn{3}{|l|}{ Race - no. (\%) } \\
\hline Asian & $367(12.1)$ & $404(13.3)$ \\
\hline Black & $103(3.4)$ & $118(3.9)$ \\
\hline Other & $246(8.1)$ & $254(8.4)$ \\
\hline White & $2318(76.4)$ & $2258(74.4)$ \\
\hline Hispanic ethnic group — no. $(\%) \ddagger$ & $903(29.8)$ & $865(28.5)$ \\
\hline \multicolumn{3}{|l|}{ Geographic region — no. (\%) } \\
\hline Africa or Near East & $142(4.7)$ & $154(5.1)$ \\
\hline Asia Pacific & $329(10.8)$ & $374(12.3)$ \\
\hline Eastern Europe & $811(26.7)$ & $776(25.6)$ \\
\hline North America & $403(13.3)$ & $404(13.3)$ \\
\hline South or Central America & $972(32.0)$ & $972(32.0)$ \\
\hline Western Europe & $377(12.4)$ & $354(11.7)$ \\
\hline Current smoking - no. (\%) & $354(11.7)$ & $355(11.7)$ \\
\hline Myocardial infarction before index ACS — no. (\%) & $672(22.1)$ & $672(22.1)$ \\
\hline \multicolumn{3}{|l|}{ Medical history at randomization — no. (\%) } \\
\hline Hypertension & $2340(77.1)$ & $2295(75.6)$ \\
\hline Percutaneous coronary intervention & $2027(66.8)$ & $2052(67.6)$ \\
\hline Coronary-artery bypass grafting & $249(8.2)$ & $258(8.5)$ \\
\hline Heart failure & $676(22.3)$ & $682(22.5)$ \\
\hline Stroke & $188(6.2)$ & $143(4.7)$ \\
\hline Peripheral arterial disease $\mathbb{Z}$ & $229(7.5)$ & $237(7.8)$ \\
\hline Atrial fibrillation & $190(6.3)$ & $176(5.8)$ \\
\hline Systolic blood pressure $-\mathrm{mm} \mathrm{Hg}$ & $130 \pm 17$ & $129 \pm 17$ \\
\hline Heart rate — beats/min & $70.2 \pm 9.9$ & $70.2 \pm 10.1$ \\
\hline HDL cholesterol - mg/dl & $42.9 \pm 10.9$ & $43.0 \pm 10.8$ \\
\hline LDL cholesterol - mg/dl & $78.2 \pm 35.2$ & $78.8 \pm 35.4$ \\
\hline $\mathrm{eGFR}-\mathrm{ml} / \mathrm{min} / 1.73 \mathrm{~m}^{2}$ & $75.2 \pm 21.4$ & $76.7 \pm 21.3$ \\
\hline \multicolumn{3}{|l|}{ Qualifying ACS event — no. (\%) } \\
\hline NSTEMI & $1183(39.0)$ & $1165(38.4)$ \\
\hline STEMI & $1317(43.4)$ & $1349(44.5)$ \\
\hline Unstable angina & $528(17.4)$ & $514(16.9)$ \\
\hline Unclassified & $6(0.2)$ & $6(0.2)$ \\
\hline
\end{tabular}




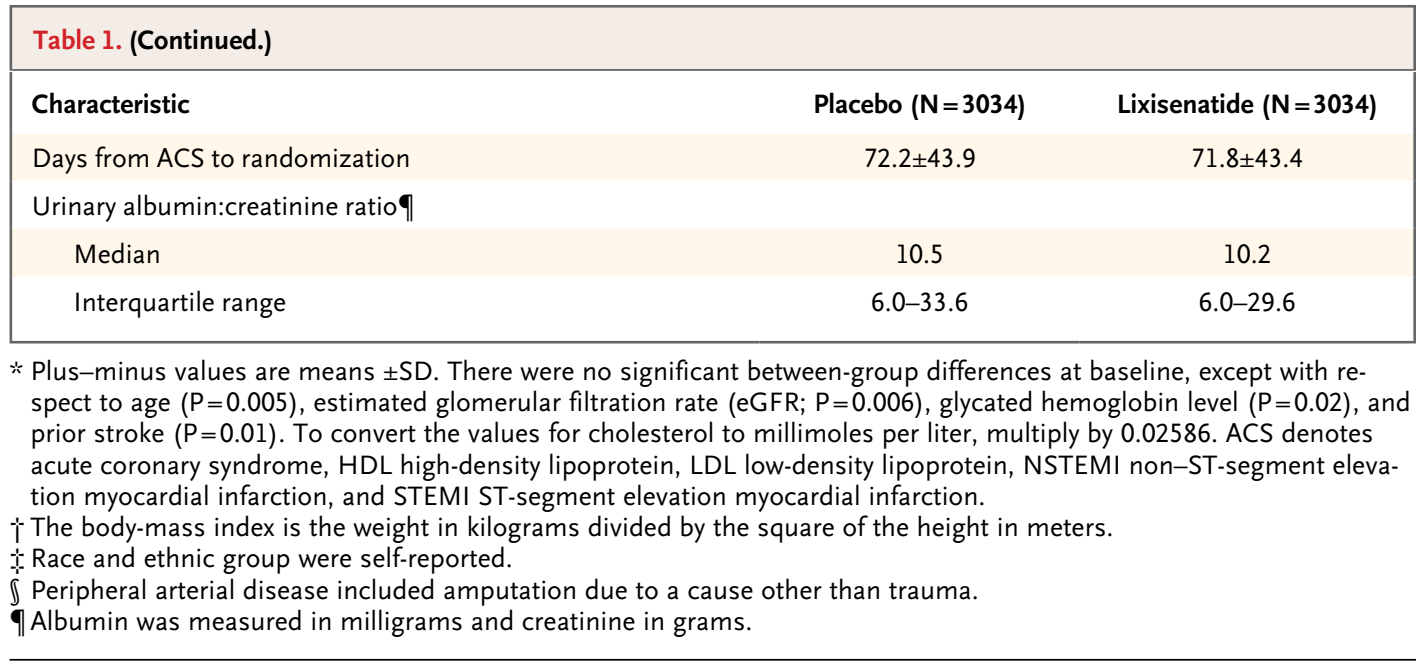

prespecified repeated-measures, mixed-effects linear regression models with patient-specific random-intercept terms and an independent within-patient residual covariance structure. Study group and visit were included in the model as factors, and baseline value was included as a covariate. Other comparisons were performed with the use of Student's t-tests, Wilcoxon rank-sum tests, and chi-square tests and were not prespecified or adjusted for multiplicity. Summary statistics include all available postbaseline data, whereas the figures exclude data beyond 40 months of follow-up ( $<10 \%$ of patients had longer follow-up).

\section{RESULTS}

\section{PATIENTS AND INTERVENTIONS}

Between July 9, 2010, and August 2, 2013, we enrolled 6068 patients from 49 countries and randomly assigned 3034 patients to lixisenatide and 3034 to placebo. All but 5 patients (3 patients in the lixisenatide group and 2 in the placebo group) received at least one dose of lixisenatide or placebo.

At the recommendation of the data and safety monitoring committee, the study went to completion. On the basis of projections made by the sponsor and shared with the executive committee without knowledge of the study-group assignments, it was estimated that the initiation of end-of-study visits on November 11, 2014, would allow for the observation of the prespecified number of adjudicated events. The last patient visit occurred on February 11, 2015. Overall, we observed that 805 patients had a confirmed primary end-point event, which provided the study with more than $95 \%$ power for the test of noninferiority and more than $88 \%$ power for the test of superiority.

The characteristics of the study groups were generally balanced at baseline (Table 1 , and Table $\mathrm{S} 1$ in the Supplementary Appendix). Nominally significant between-group differences were observed in 4 of the 35 baseline comparisons (those regarding age, eGFR, glycated hemoglobin level, and prior stroke) (Table 1, and Table S1 in the Supplementary Appendix).

The median follow-up was 25 months in each study group. Among patients who did not die, $96.3 \%$ of the patients in the lixisenatide group and $96.1 \%$ of those in the placebo group completed the study. Vital status was ascertained at the end of the study in all but 29 patients (1.0\%) in the lixisenatide group and in all but 42 (1.4\%) in the placebo group.

The mean duration of exposure to study medication was 690 days in the lixisenatide group and 712 days in the placebo group. Excluding the 51 patients in the lixisenatide group and 41 in the placebo group who were taking the study medication on the day of death, the study medication was permanently discontinued in 833 patients (27.5\%) in the lixisenatide group and in 727 $(24.0 \%)$ in the placebo group $(\mathrm{P}=0.002)$. Among patients who received at least one dose of lixisenatide or placebo, 2591 of 3031 patients (85.5\%) in the lixisenatide group were taking the maximum dose of $20 \mu \mathrm{g}$ at the time of their last dose of lixisenatide, and 2926 of 3032 patients (96.5\%) 


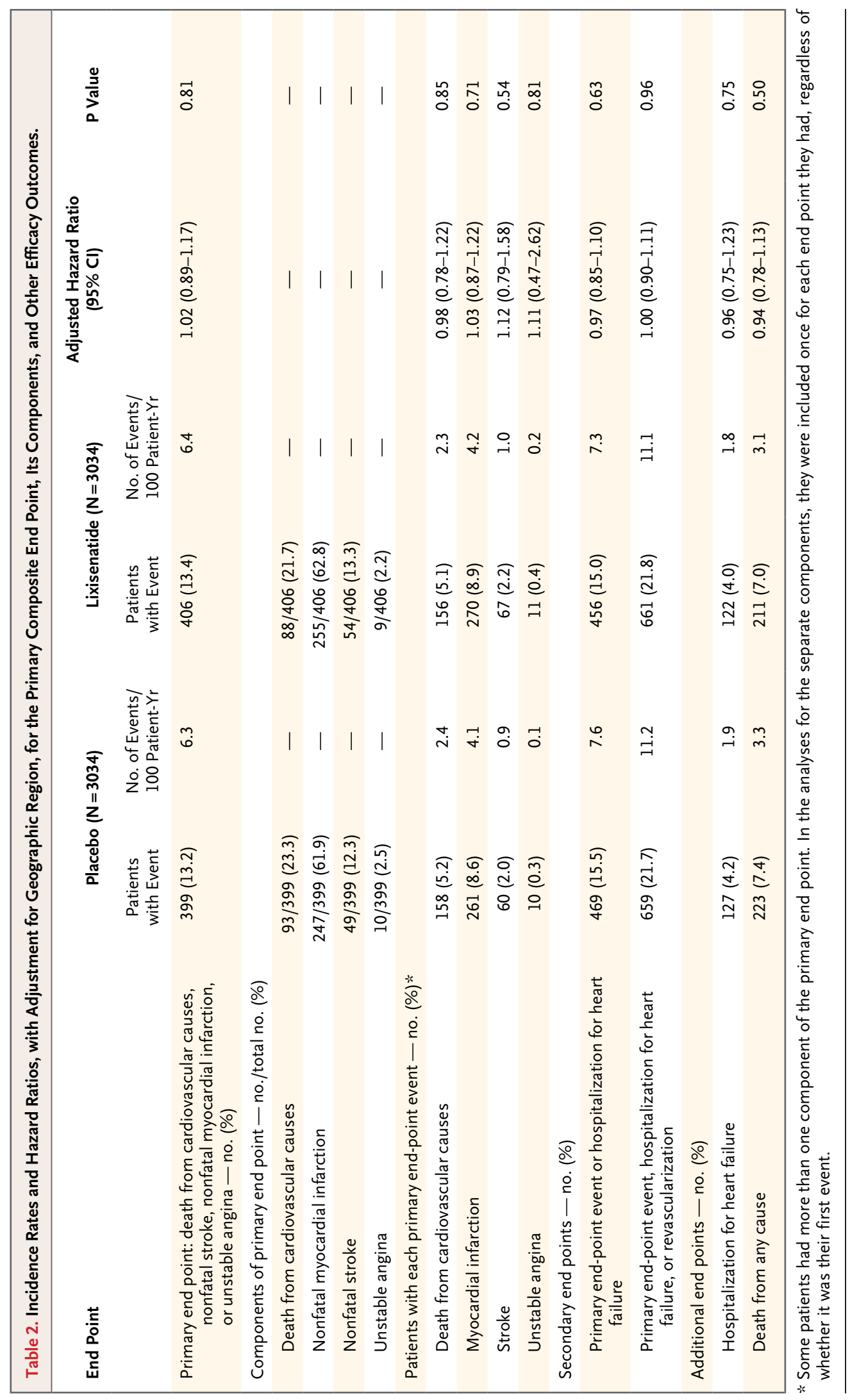


in the placebo group were taking the volumematched equivalent for this maximum dose.

\section{CARDIOVASCULAR END POINTS}

The primary end point occurred in 406 patients $(13.4 \%)$ in the lixisenatide group and in 399 $(13.2 \%)$ in the placebo group. For this firstoccurrence composite end point in the time-toevent analysis, the contributions from each component event are shown in Table 2. The hazard ratio for the primary end point in the lixisenatide group as compared with the placebo group was 1.02 ( $95 \%$ confidence interval [CI], 0.89 to 1.17); the upper boundary of the $95 \%$ confidence interval excluded 1.3 but not 1.0, which showed the noninferiority of lixisenatide to placebo $(\mathrm{P}<0.001)$ but not superiority ( $\mathrm{P}=0.81)$ (Fig. 1$)$.

Sensitivity analyses that excluded events occurring more than 30 days after discontinuation of lixisenatide or placebo and that were adjusted for baseline imbalances produced similar results (Table S2 in the Supplementary Appendix). No significant study-group interactions were observed for the primary end point in the prespecified subgroups or in the post hoc subgroups, including the subgroup defined according to history or no history of heart failure (Fig. S1 in the Supplementary Appendix).

Regarding the separate cardiovascular components of the primary end point, the frequency of each was similar in the two study groups (Table 2). A total of 156 patients in the lixisenatide group and 158 in the placebo group died from cardiovascular causes (hazard ratio, 0.98; $95 \%$ CI, 0.78 to 1.22 ), a total of 270 patients in the lixisenatide group and 261 in the placebo group had a fatal or nonfatal myocardial infarction (hazard ratio, 1.03 ; 95\% CI, 0.87 to 1.22 ), a total of 67 patients in the lixisenatide group and 60 in the placebo group had a fatal or nonfatal stroke (hazard ratio, 1.12; 95\% CI, 0.79 to 1.58 ), and a total of 11 patients in the lixisenatide group and 10 in the placebo group were hospitalized for unstable angina (hazard ratio, 1.11; $95 \%$ CI, 0.47 to 2.62 ).

When hospitalization for heart failure was added to the primary composite end point, 456 patients $(15.0 \%)$ in the lixisenatide group and $469(15.5 \%)$ in the placebo group had an event in this expanded end point (hazard ratio, 0.97; $95 \%$ CI, 0.85 to 1.10). The further addition of coronary revascularization procedure to the ex-

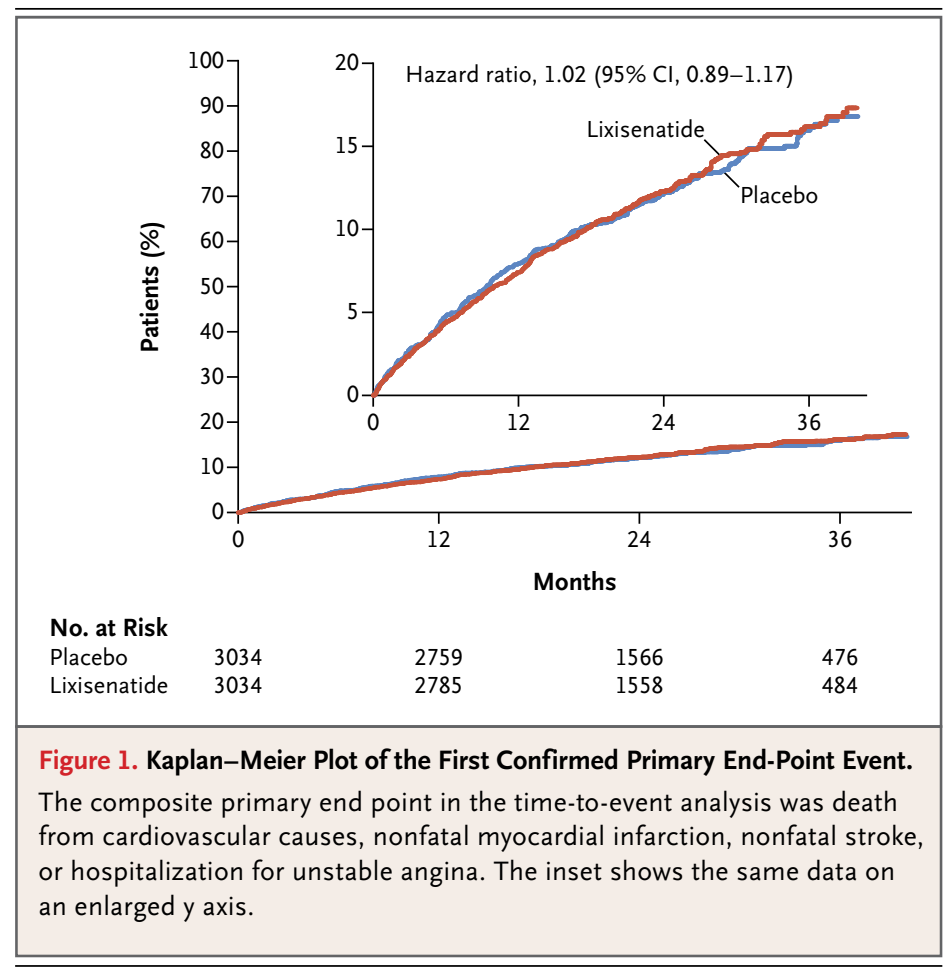

panded composite end point resulted in 661 patients $(21.8 \%)$ in the lixisenatide group and 659 (21.7\%) in the placebo group having at least one of these adjudicated cardiovascular end points (hazard ratio, 1.00; 95\% CI, 0.90 to 1.11) (Table 2).

As a separate end point, hospitalization for heart failure occurred in 122 patients $(4.0 \%)$ in the lixisenatide group and in 127 (4.2\%) in the placebo group (hazard ratio, 0.96; 95\% CI, 0.75 to 1.23) (Table 2). Death from any cause was reported in 211 patients $(7.0 \%)$ in the lixisenatide group and in 223 (7.4\%) in the placebo group (hazard ratio, $0.94 ; 95 \% \mathrm{CI}, 0.78$ to 1.13 ) (Table 2). Deaths that were adjudicated as having resulted from noncardiovascular causes occurred in 46 patients $(1.5 \%)$ in the lixisenatide group and in $58(1.9 \%)$ in the placebo group.

\section{CLINICAL AND METABOLIC EFFECTS}

Although the management of glucose levels in individual patients was at the discretion of the treating physicians, the reduction in glycated hemoglobin values from baseline to week 12 was significantly greater among patients randomly assigned to lixisenatide than among those assigned to placebo $(-0.6$ percentage points vs. -0.2 percentage points, $\mathrm{P}<0.001)$. The betweengroup difference (lixisenatide minus placebo) 


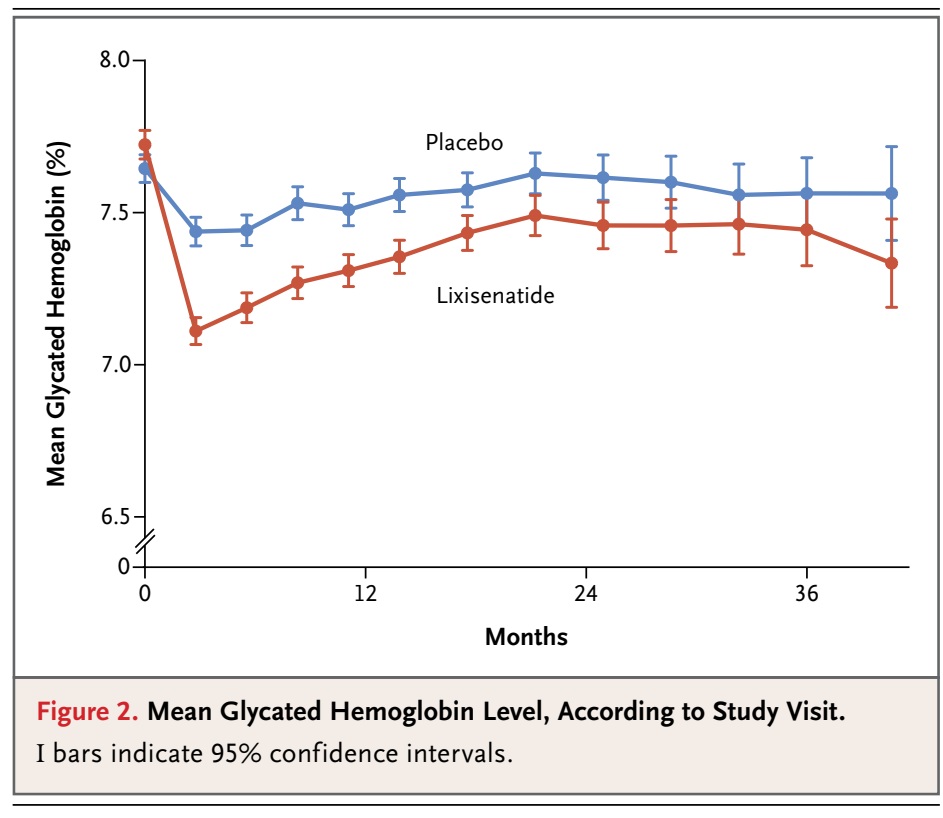

was sustained, with an average difference across all visits of -0.27 percentage points $(95 \% \mathrm{CI}$, -0.31 to -0.22 ; $\mathrm{P}<0.001$ ) (Fig. 2). Hypoglycemic episodes during the study were reported in 504 patients $(16.6 \%)$ in the lixisenatide group and in $462(15.2 \%)$ in the placebo group ( $\mathrm{P}=0.14)$. Serious hypoglycemic episodes (requiring assistance from another person) were numerically less frequent with lixisenatide (14 patients reporting 16 events) than with placebo ( 24 patients reporting 37 events).

A modest but significant between-group difference in the change in body weight from baseline was apparent at 12 weeks $(-0.6 \mathrm{~kg}$ in the lixisenatide group vs. $-0.0 \mathrm{~kg}$ in the placebo group, $\mathrm{P}<0.001)$. This relative weight difference was sustained throughout the follow-up period, with an average between-group difference (lixisenatide minus placebo) across all visits of $-0.7 \mathrm{~kg}$ (95\% CI, -0.9 to $-0.5 ; \mathrm{P}<0.001$ ) (Fig. S2 in the Supplementary Appendix).

A modest relative difference (lixisenatide minus placebo) in systolic blood pressure in the lixisenatide group as compared with the placebo group was sustained throughout follow-up, with an average difference across all visits of $-0.8 \mathrm{~mm} \mathrm{Hg}$ (95\% CI, -1.3 to -0.3 ) in favor of lixisenatide $(\mathrm{P}=0.001)$ (Fig. $\mathrm{S} 3$ in the Supplementary Appendix). A small but significant difference in heart rate was observed, with, on average, 0.4 more beats per minute ( $95 \% \mathrm{CI}, 0.1$ to 0.6 ) in the lix- isenatide group than in the placebo group across all visits $(\mathrm{P}=0.01)$. This result appeared to be due predominantly to an increase of 1 beat per minute at weeks 2 and 6 that was not detected at later time points (Fig. S4 in the Supplementary Appendix).

Although the prespecified analysis of the percentage change in the urinary albumin-tocreatinine ratio (with albumin measured in milligrams and creatinine measured in grams) from baseline to 108 weeks showed a modest difference in favor of lixisenatide over placebo $(24 \%$ vs. $34 \%, \mathrm{P}=0.004$ ), the median values at baseline (ratio, 10 in each study group) and follow-up (ratio, 12 in the lixisenatide group and 13 in the placebo group) were clinically similar (Table S3 in the Supplementary Appendix). In a post hoc model that included further adjustment for the glycated hemoglobin level as measured at baseline and at 3 months after randomization, this difference was attenuated $(\mathrm{P}=0.07)$ (Table S3 in the Supplementary Appendix).

\section{ADVERSE EVENTS}

Adverse events that led to the permanent discontinuation of lixisenatide or placebo occurred in 347 patients $(11.4 \%)$ in the lixisenatide group and in $217(7.2 \%)$ in the placebo group $(\mathrm{P}<0.001)$. The most common adverse event leading to discontinuation was a gastrointestinal event, which was reported in 149 patients $(4.9 \%)$ in the lixisenatide group and in $37(1.2 \%)$ in the placebo group $(\mathrm{P}<0.001)$ (Table $\mathrm{S} 4$ in the Supplementary Appendix). Within this category, nausea or vomiting accounted for most of the between-group difference in the discontinuation of lixisenatide or placebo, with 91 patients (3.0\%) in the lixisenatide group and $11(0.4 \%)$ in the placebo group discontinuing because of nausea and 33 $(1.1 \%)$ in the lixisenatide group and $5(0.2 \%)$ in the placebo group discontinuing because of vomiting $(\mathrm{P}<0.001$ for both comparisons).

Serious adverse events were reported in 625 patients (20.6\%) in the lixisenatide group and in $669(22.1 \%)$ in the placebo group. Serious adverse events that were attributed to the gastrointestinal system were reported in 66 patients $(2.2 \%)$ in the lixisenatide group and in 81 (2.7\%) in the placebo group (Table 3). While the patients were receiving lixisenatide or placebo, pancreatitis occurred in 5 patients in the lixisenatide group and in 8 in the placebo group; 3 patients 
in the lixisenatide group and 9 in the placebo group received a diagnosis of pancreatic cancer. Systemic allergic reactions occurred in $27 \mathrm{pa}$ tients in the lixisenatide group and in 25 in the placebo group.

\section{DISCUSSION}

In patients with type 2 diabetes and a recent acute coronary syndrome, treatment with the GLP-1-receptor agonist lixisenatide, added to conventional therapy, was not associated with a significant difference in rates of cardiovascular events as compared with conventional therapy plus placebo. This conclusion is supported by additional sensitivity analyses that excluded events occurring more than 30 days after the discontinuation of lixisenatide or placebo, as well as by a post hoc analysis in which the model was adjusted for minor between-group imbalances observed at baseline (Table S2 in the Supplementary Appendix).

This neutral influence of lixisenatide on cardiovascular end points was reflected in the individual components of the primary composite end point and was consistent across multiple prespecified subgroups. The targeting of a population that had type 2 diabetes and a high cardiovascular risk due to a recent acute coronary syndrome with a protocol that permitted the adjustment of glucose-lowering therapies in each group, with the expectation of similar glycemic control, resulted in modest differences in the glycated hemoglobin level and allowed us to focus on cardiovascular actions of the GLP-1-receptor agonist that were unrelated to glycemic factors. ${ }^{26}$

Heart failure is a major cardiovascular burden with severe adverse consequences, including a substantial increase in the risk of death among patients with type 2 diabetes. ${ }^{10,28}$ Particularly worrisome is a meta-analysis of 14 trials of glucose-lowering therapies that had enrolled more than 95,000 patients with type 2 diabetes and showed that both the peroxisome proliferator-activated receptor and dipeptidyl peptidase-4 inhibitor (DPP-4) classes of glucose-lowering therapies were associated with increased rates of heart failure. ${ }^{29}$

However, subsequent to that analysis, a recent major trial showed that the use of sitagliptin (another DPP-4 inhibitor) was not associated with changes in the rates of hospitalization for
Table 3. Serious Adverse Events.*

$\begin{array}{ccc} & \text { Placebo } & \text { Lixisenatide } \\ \text { Event } & (\mathrm{N}=3032) & (\mathrm{N}=3031)\end{array}$

no. of patients with event (\%)

Any event

669 (22.1)

625 (20.6)

Blood or lymphatic event

$14(0.5)$

$14(0.5)$

Cardiac event $\uparrow$

107 (3.5)

$83(2.7)$

Ear or labyrinth event

$4(0.1)$

$5(0.2)$

Endocrine event

$3(0.1)$

$2(0.1)$

Eye event

$13(0.4)$

$9(0.3)$

Gastrointestinal event

$81(2.7)$

$66(2.2)$

General event

58 (1.9)

64 (2.1)

Hepatobiliary event

$28(0.9)$

36 (1.2)

Immune system event

$2(0.1)$

$4(0.1)$

Infection

$186(6.1)$

173 (5.7)

Injury or poisoning

$50(1.6)$

$44(1.5)$

Investigationst

$19(0.6)$

$10(0.3)$

Metabolism or nutrition event

57 (1.9)

33 (1.1)

Musculoskeletal event

35 (1.2)

32 (1.1)

Neoplasm

$61(2.0)$

$72(2.4)$

Nervous system event

$53(1.7)$

47 (1.6)

Psychiatric event

$5(0.2)$

$9(0.3)$

Renal or urinary event

48 (1.6)

48 (1.6)

Reproductive system event

$5(0.2)$

$13(0.4)$

Respiratory or thoracic event

58 (1.9)

$58(1.9)$

Skin or subcutaneous tissue event

Social circumstances

$18(0.6)$

$14(0.5)$

\section{0}

$1(<0.1)$

Surgical or medical procedure

$6(0.2)$

$6(0.2)$

Vascular event

$71(2.3)$

$59(1.9)$

* Events were assessed with the use of the classifications in the Medical Dictionary for Regulatory Activities (MedDRA), version 15.0.

$\uparrow$ Adjudicated cardiovascular events were not required to be submitted as serious adverse events unless they were considered by the investigator to be possibly drug-related.

$\uparrow$ Investigations included abnormal results on laboratory tests or physical examination. The most common MedDRA preferred terms used were "alanine aminotransferase increased" (in seven patients in the placebo group and in two in the lixisenatide group) and "blood glucose increased" (in four in the placebo group and in one in the lixisenatide group).

heart failure. ${ }^{30}$ Our finding of a neutral effect on the incidence of hospitalization for heart failure among patients randomly assigned to lixisenatide, which was consistent in the subgroups of patients with a history of heart failure and those without such a history (Table S5 in the Supplementary Appendix), offers new safety information regarding this GLP-1-receptor agonist. 
Mortality among patients with type 2 diabetes, although higher than in the general population, varies widely depending on cardiovascular and renal coexisting conditions. ${ }^{31,32}$ The overall annualized mortality in our trial was on the higher end of the risk spectrum that has been observed in other clinical trials involving patients with diabetes. Strides have been made to address the nonglycemic risk factors for these patients. ${ }^{33-36}$

These advances in the standard of care have increased the difficulty of showing incremental improvements in cardiovascular prognosis with intensification of glucose-lowering or lifestyle measures. ${ }^{2,37}$ The few favorable demonstrations of reduced rates of cardiovascular events with predominantly glucose-lowering therapies have required more protracted follow-up than routinely occurs in clinical trials. ${ }^{4,7}$ Although our study had only approximately 2 years of follow-up, suf- ficient numbers of cardiovascular events were observed so that we could reasonably exclude a major nonglycemic cardiovascular benefit ${ }^{21}$ as well as an unanticipated harm of lixisenatide.

In conclusion, among patients with type 2 diabetes and a recent acute coronary syndrome, treatment with lixisenatide resulted in rates of major cardiovascular events, including heart failure and death from any cause, that were similar to those observed with placebo. The neutral cardiovascular profile associated with lixisenatide will inform physicians' and patients' decisions regarding the use of this agent as an adjunctive therapy to control the glycated hemoglobin level safely, with no observed augmentation of the risks of hypoglycemia or pancreatitis.

Supported by Sanofi.

Disclosure forms provided by the authors are available with the full text of this article at NEJM.org.

\section{REFERENCES}

1. UK Prospective Diabetes Study (UKPDS) Group. Intensive blood-glucose control with sulphonylureas or insulin compared with conventional treatment and risk of complications in patients with type 2 diabetes (UKPDS 33). Lancet 1998;352:837-53.

2. Gerstein HC, Miller ME, Byington RP, et al. Effects of intensive glucose lowering in type 2 diabetes. N Engl J Med 2008;358: 2545-59.

3. Chew EY, Ambrosius WT, Davis MD, et al. Effects of medical therapies on retinopathy progression in type 2 diabetes. N Engl J Med 2010;363:233-44.

4. Holman RR, Paul SK, Bethel MA, Matthews DR, Neil HA. 10-Year follow-up of intensive glucose control in type 2 diabetes. N Engl J Med 2008;359:1577-89.

5. Gerstein $\mathrm{HC}$, Miller ME, Ismail-Beigi F, et al. Effects of intensive glycaemic control on ischaemic heart disease: analysis of data from the randomised, controlled ACCORD trial. Lancet 2014;384:1936-41. 6. Turnbull FM, Abraira C, Anderson RJ, et al. Intensive glucose control and macrovascular outcomes in type 2 diabetes. Diabetologia 2009;52:2288-98.

7. Hayward RA, Reaven PD, Wiitala WL, et al. Follow-up of glycemic control and cardiovascular outcomes in type 2 diabetes. N Engl J Med 2015;372:2197-206.

8. Lago RM, Singh PP, Nesto RW. Congestive heart failure and cardiovascular death in patients with prediabetes and type 2 diabetes given thiazolidinediones: a meta-analysis of randomised clinical trials. Lancet 2007;370:1129-36.

9. Goldfine $\mathrm{AB}$. Assessing the cardiovascular safety of diabetes therapies. N Engl J Med 2008;359:1092-5.

10. McMurray JJ, Gerstein HC, Holman
RR, Pfeffer MA. Heart failure: a cardiovascular outcome in diabetes that can no longer be ignored. Lancet Diabetes Endocrinol 2014;2:843-51.

11. Diabetes mellitus - evaluating cardiovascular risk in new antidiabetic therapies to treat type 2 diabetes. Silver Spring, MD: Department of Health and Human Services, Center for Drug Evaluation and Research, 2008.

12. European Medicines Agency guideline on clinical investigation of medicinal products in the treatment or prevention of diabetes mellitus. London: Committee for Medicinal Products for Human Use, 2012. 13. Hiatt WR, Kaul S, Smith RJ. The cardiovascular safety of diabetes drugs - insights from the rosiglitazone experience. N Engl J Med 2013;369:1285-7.

14. Drucker DJ. The biology of incretin hormones. Cell Metab 2006;3:153-65.

15. Noyan-Ashraf MH, Momen MA, Ban K, et al. GLP-1R agonist liraglutide activates cytoprotective pathways and improves outcomes after experimental myocardial infarction in mice. Diabetes 2009;58:97583.

16. Timmers L, Henriques JP, de Kleijn $\mathrm{DP}$, et al. Exenatide reduces infarct size and improves cardiac function in a porcine model of ischemia and reperfusion injury. J Am Coll Cardiol 2009;53:501-10. 17. Nikolaidis LA, Mankad S, Sokos GG et al. Effects of glucagon-like peptide-1 in patients with acute myocardial infarction and left ventricular dysfunction after successful reperfusion. Circulation 2004;109: 962-5.

18. Woo JS, Kim W, Ha SJ, et al. Cardioprotective effects of exenatide in patients with ST-segment-elevation myocardial in- farction undergoing primary percutaneous coronary intervention: results of exenatide myocardial protection in revascularization study. Arterioscler Thromb Vasc Biol 2013;33:2252-60.

19. Nathanson D, Ullman B, Löfström U, et al. Effects of intravenous exenatide in type 2 diabetic patients with congestive heart failure: a double-blind, randomised controlled clinical trial of efficacy and safety. Diabetologia 2012;55:926-35.

20. Saraiva FK, Sposito AC. Cardiovascular effects of glucagon-like peptide 1 (GLP-1) receptor agonists. Cardiovasc Diabetol 2014;13:142

21. Smilowitz NR, Donnino R, Schwartzbard A. Glucagon-like peptide-1 receptor agonists for diabetes mellitus: a role in cardiovascular disease. Circulation 2014; 129:2305-12

22. Fonseca VA, Alvarado-Ruiz R, Raccah D, Boka G, Miossec P, Gerich JE. Efficacy and safety of the once-daily GLP-1 receptor agonist lixisenatide in monotherapy: a randomized, double-blind, placebocontrolled trial in patients with type 2 diabetes (GetGoal-Mono). Diabetes Care 2012;35:1225-31.

23. Bolli GB, Munteanu M, Dotsenko S, et al. Efficacy and safety of lixisenatide once daily vs. placebo in people with type 2 diabetes insufficiently controlled on metformin (GetGoal-F1). Diabet Med 2014; 31:176-84.

24. Riddle MC, Aronson R, Home P, et al. Adding once-daily lixisenatide for type 2 diabetes inadequately controlled by established basal insulin: a 24-week, randomized, placebo-controlled comparison (GetGoal-L). Diabetes Care 2013;36:248996. 
25. Meier JJ. GLP-1 receptor agonists for individualized treatment of type 2 diabetes mellitus. Nat Rev Endocrinol 2012;8: 728-42.

26. Bentley-Lewis R, Aguilar D, Riddle MC, et al. Rationale, design, and baseline characteristics in Evaluation of LIXisenatide in Acute Coronary Syndrome, a long-term cardiovascular end point trial of lixisenatide versus placebo. Am Heart J 2015; 169(5):631-638.e7.

27. Yang F, Stewart M, Ye J, DeMets D. Type 2 diabetes mellitus development programs in the new regulatory environment with cardiovascular safety requirements. Diabetes Metab Syndr Obes 2015; 8:315-25.

28. Jhund PS, McMurray JJV, Chaturvedi N, et al. Mortality following a cardiovascular or renal event in patients with type 2 diabetes in the ALTITUDE trial. Eur Heart J 2015;36:2463-9.

29. Udell JA, Cavender MA, Bhatt DI
Chatterjee S, Farkouh ME, Scirica BM. Glucose-lowering drugs or strategies and cardiovascular outcomes in patients with or at risk for type 2 diabetes: a meta-analysis of randomised controlled trials. Lancet Diabetes Endocrinol 2015;3:356-66.

30. Green JB, Bethel MA, Armstrong PW, et al. Effect of sitagliptin on cardiovascular outcomes in type 2 diabetes. $\mathrm{N}$ Engl J Med 2015;373:232-42

31. Seshasai SR, Kaptoge S, Thompson A, et al. Diabetes mellitus, fasting glucose, and risk of cause-specific death. $\mathrm{N}$ Engl J Med 2011;364:829-41.

32. Barkoudah E, Skali H, Uno H, Solomon SD, Pfeffer MA. Mortality rates in trials of subjects with type 2 diabetes. J Am Heart Assoc 2012;1:8-15.

33. Ali MK, Bullard KM, Saaddine JB, Cowie CC, Imperatore G, Gregg EW. Achievement of goals in U.S. diabetes care, 1999-2010. N Engl J Med 2013;368: 1613-24.
34. Griffin SJ, Borch-Johnsen K, Davies MJ, et al. Effect of early intensive multifactorial therapy on 5-year cardiovascular outcomes in individuals with type 2 diabetes detected by screening (ADDITION-Europe): a cluster-randomised trial. Lancet 2011; 378:156-67.

35. American Diabetes Association. Standards of medical care in diabetes - 2012. Diabetes Care 2012;35:Suppl 1:S11-63.

36. Fox CS, Golden SH, Anderson C, et al. Update on prevention of cardiovascular disease in adults with type 2 diabetes mellitus in light of recent evidence: a scientific statement from the American Heart Association and the American Diabetes Association. Circulation 2015;132:691-718. 37. Wing RR, Bolin P, Brancati FL, et al. Cardiovascular effects of intensive lifestyle intervention in type 2 diabetes. $\mathrm{N}$ Engl J Med 2013;369:145-54.

Copyright (c) 2015 Massachusetts Medical Society. 